\title{
O ENSINO DA LEITURA EM SALA DE AULA COM CRIANÇAS: A TERTÚLIA LITERÁRIA DIALÓGICA*
}

\author{
Vanessa Cristina Girotto, \\ da Universidade Federal de Alfenas \\ Rosel Rodrigues de Mello, \\ da Universidade Federal de São Carlos
}

\begin{abstract}
Resumo: O presente artigo tem como objetivo apresentar os resultados de uma pesquisa de doutorado (2011), cujo tema é a leitura dialógica. Trata-se da leitura de literatura clássica para reforçar aprendizagens e estabelecer conexões com a vida. Foram retomadas, também, algumas investigações que vêm acontecendo no campo da leitura e da escrita em âmbito nacional e seus avanços, no intuito de ampliar o debate. Tal atividade foi realizada pioneiramente em duas salas de aula de uma escola pública do interior do estado de São Paulo e teve como orientação a metodologia comunicativo-crítica, cuja base está na análise da realidade em parceria com os sujeitos. Como resultados destacamos os impactos positivos de uma leitura dialógica nas práticas docentes, no contexto e nas aprendizagens de crianças em sala de aula.
\end{abstract}

Palavras-chave: Leitura. Diálogo. Literatura. Sala de aula.

\section{INTRODUÇÃO}

O tema central tratado nesse artigo refere-se à leitura e à escrita, por entendermos a estreita e essencial relação estabelecida entre esses termos e as necessidades dos sujeitos postas no atual contexto da sociedade. Contexto este, marcado por uma transição da sociedade industrial para a sociedade da informação e do conhecimento, conforme indicam Castells (1994), Aubert et al. (2008) e Flecha (1997), em que são priorizados o processamento e a seleção 
da informação. Entendemos, dessa forma, o papel da escola no sentido de oferecer os instrumentos necessários para que os sujeitos possam apropriarse dessa prática, ou seja, selecionar a informação e manejá-la no sentido de efetivar seu processo de ensino e de aprendizagem.

Esse processo de revolução tecnológica, que marca o século XXI, traz também novas questões que passam a orientar nossa vida, como novos valores, normas sociais, padrões e escolhas nos diferentes âmbitos: familiar, profissional e na vida amorosa. Ao mesmo tempo que aumenta a liberdade de opções, aumentam-se, também, os riscos e, consequentemente, a necessidade de dialogar em torno das escolhas, das decisões em relação ao nosso presente e futuro. Entende-se que o diálogo entra para substituir as relações antes baseadas somente na autoridade. Tal mudança é denominada "giro dialógico" (AUBERT et al., 2008).

Em uma sociedade globalizada e informacional, conforme apontam Aubert et al. (2008), é necessária a busca por uma educação que acompanhe esse movimento de mudança dialógica. Em qualquer área do conhecimento, uma teoria não é certa, boa ou eficaz para sempre; é necessário reconhecer as contribuições anteriores e poder avançar sempre.

Nesse sentido, rechaçamos os altos índices de fracasso escolar que temos presenciado e, ainda, as teorias da aprendizagem que vem se embasando em argumentos "científicos" para justificar ações educativas excludentes. Trazemos para a discussão uma concepção que busca uma aprendizagem orientada rumo ao diálogo, na tentativa de apontar algumas respostas para os desafios educativos postos na atualidade.

Essa concepção, que parte de uma aprendizagem que é dialógica, centra-se especialmente nas ideias de Freire (2005), Habermas (1987), Flecha (1997), Vygotsky (2009), Aubert et al. (2008), cujos estudos incorporam o diálogo não somente na teoria, mas também como fundamento de práticas educativas de êxito para todas as pessoas.

Nessa linha de pensamento, identificamos a ação comunicativa relatada por Habermas (1987) como a interação de pelo menos dois sujeitos capazes de linguagem e ação, que estabelecem uma relação interpessoal com meios verbais ou não verbais. Os sujeitos buscam entendimento sobre uma situação de ação para poder assim coordenar de comum acordo seus planos de ação e posteriormente suas ações. O conceito central, para este autor, é o "da interpretação e refere-se primordialmente à negociação de definições da situação suscetível de consenso"1 (p. 124).

Temos também os estudos de Vygotsky (2009), em que o autor afirma que a linguagem é a ferramenta cultural mais importante e inseparável da 
atividade humana. Sua função, segundo o autor, não é outra senão a de servir como condutor da influência humana sobre o objeto da atividade, ou seja, é um meio através do qual a atividade humana externa aspira a dominar e a triunfar sobre a natureza.

Ao afirmar que a ação constitui o homem e a mulher, concordamos com Freire (2006), que afirma que o homem se faz um ser de práxis, ou seja, de ação e de reflexão, por ser considerado um ser que trabalha, que tem pensamento e linguagem, que pode atuar e refletir sobre si mesmo e sobre sua própria atividade. Sua presença no mundo compreende uma ação sobre ele, um defrontar-se com ele, ou seja, sua vida é um estar sendo no mundo e com o mundo (2006, p. 39).

Assim, destacamos a importância de reconhecer que nem a sociedade nem a educação são resultados apenas do sistema ou mesmo das estruturas. Ou seja, como as pessoas e os movimentos geram a sociedade e a educação, a partir de relações intersubjetivas estabelecidas, dessa forma também podem transformá-las e transformar-se. Em consonância com tais autores, a presente proposta traz um conceito de leitura pautada no diálogo, na linguagem e na ação: trata-se do conceito de leitura dialógica. Antes, porém, enfatizaremos algumas concepções de leitura que vem sendo estabelecidas na escola.

\section{A LeITURA NA ESCOLA: ALGUMAS CONCEPÇÕES}

Podemos tomar o aparecimento da escola como instituição responsável pelo ensino das letras. Todavia, foi somente no século XVII da nossa era que esta instituição, aliada à atividade de ensinar a ler e escrever, começou sua expansão, atingindo todas as áreas e segmentos sociais. Nesse ponto começa também a valorização da alfabetização, como etapa básica do ensino.

A alfabetização tem sido um tema amplamente discutido na sociedade, especialmente por especialistas que voltam o olhar sobre a temática educacional. Apesar desses estudos, notamos que há muitas décadas se observam os mesmos problemas: evasão escolar, dificuldades de aprendizagem, dificuldades de alfabetização, além dos baixos índices de aprovação apontados pelas avaliações nacionais. Tal evidência aponta para a necessidade de uma reestruturação do ensino, questão que vem recebendo atenção especial de órgãos do governo e de especialistas nas últimas décadas.

Ao traçar um pequeno panorama das produções científicas das últimas três décadas, no Brasil, foi possível identificar algumas transformações não somente da lógica, mas também das práticas a serem trabalhadas no âmbito escolar. A partir da grande produção científica na área, nos últimos 
dez anos ${ }^{2}$ tornou-se possível pensar sobre questões envolvidas no ensino e na aprendizagem da língua; consequentemente pode-se falar que o debate vem avançando rumo à efetivação da qualidade e ao acesso ao ensino e à aprendizagem da leitura.

É possível encontrar no conceito construtivista de ensino a base para a formulação de políticas na área da educação. Entende-se, agora, que as crianças sabem muito mais do que se poderia supor até então e, assim, se evidencia que a alfabetização não é apenas um processo de memorizar. Para aprender a ler e a escrever "o aluno precisa construir um conhecimento de natureza conceitual: ele precisa compreender não só o que a escrita representa, mas também de que forma ela representa graficamente a linguagem" (PCN, 2001, p. 21).

Seguramente, a divulgação dessa nova proposta didática vem contribuir para o trabalho de professoras em salas de aula, oferecendo elementos para repensar um ensino, muitas vezes, apenas conteudista e, como ressaltava Freire (2005), ensino baseado em uma "educação bancária", advinda de longo processo desumanizador. Nesse sentido, entendemos os vários avanços a partir do enfoque construtivista, bem como as muitas contribuições de outras áreas, como a psicologia e a linguística, que foram incorporadas na discussão da melhoria da qualidade da educação. Porém, pensamos que esse debate atual ainda não incorporou elementos concretos na base da transformação da escola, que atenda à diversidade e ofereça um ensino de máxima qualidade para todas as pessoas.

Dessa forma, o reconhecimento desse avanço não nos impede de criticar os limites dessa abordagem conceitual, que vem produzindo grandes equívocos e distorções no papel da educação. Tais equívocos, provenientes tanto da interpretação equivocada do construtivismo quanto da sua (in) consequente aplicação em nosso país, podem ser revelados nas inúmeras pesquisas sobre o fracasso do sistema escolar brasileiro.

Soares (2003) ressalta que tal fracasso pode ser identificado nos altos índices de precário ou nulo desempenho em provas de leitura, denunciando grandes contingentes de alunos não alfabetizados ou semialfabetizados depois de quatro, seis, oito anos de escolarização. Podemos constatar estes dados não somente nas avaliações internas à escola, como também nos altos índices de reprovação, repetência, evasão, explícitos nas avaliações como Saresp, Saeb, Enem, PISA, revelando o descaso ao longo de todo o ensino fundamental e médio.

Na nossa sociedade temos visto e convivido com o estabelecimento de leis que trabalham na promoção de uma melhor qualidade da educação, 
debates nas Universidades, movimentos sociais que reivindicam garantias desses direitos etc., porém ainda há muito a fazer. Acreditamos que a verdadeira melhoria se concretizará quando a escola deixar de ausentar-se do diálogo com as diferentes culturas e começar a incorporar todas as falas e anseios provenientes das diferentes classes e orientações sociais.

Buscando descrever, analisar, interpretar e interferir nesse quadro, pesquisadores nacionais e de outros países foram redefinindo alfabetização, domínio mais elaborado do código escrito, gerando conceitos como o de letramento, amplamente difundido no debate nacional e internacional. ${ }^{3}$ Tal conceito já penetrou as políticas públicas e, portanto, tem interferido nas práticas educacionais, pressionando-as ou modificando-as, desde a década de 1990.

Sabemos que na atualidade os termos "analfabetismo" e "iletrismo" surgem na mídia, na literatura acadêmica e nas políticas públicas, referindo-se ao insucesso da escola em garantir a aprendizagem da leitura e da escrita aos que nela ingressam (hoje, a quase totalidade das crianças e jovens). Se o acesso à escola e às práticas escolares de escrita e de leitura quase se universalizou, a garantia da apropriação dos instrumentos ainda não se efetivou para parte significativa da população.

Soares (2003) indica que, em nível internacional, cabe falar da proposta de reformulação, pela Unesco (Organização das Nações Unidas para a Educação, a Ciência e a Cultura), "da ampliação do conceito de literate para functionally literate, e, portanto, [da] sugestão de que as avaliações internacionais sobre o domínio de competências de leitura e de escrita fossem além do medir apenas a capacidade de saber ler e escrever" (p. 6).

No Brasil, os Parâmetros Curriculares Nacionais (PCN), por exemplo, ao abordarem o compromisso da escola com um projeto educativo de democratização social e cultural, atribuindo a ela a função e a responsabilidade de garantir a todos os seus alunos(as) o acesso aos saberes linguísticos necessários para o exercício da cidadania, afirmam que é necessário considerar o grau de letramento das comunidades em que vivem os alunos.

De acordo com os PCN, a aptidão para ler e produzir textos - dos mais variados gêneros e temas - com proficiência é o mais significativo indicador de um bom desempenho linguístico e, consequentemente, de letramento. Afirma-se, ainda, que um escritor competente dever saber selecionar o gênero apropriado aos seus objetivos e à circunstância em que realizará seu discurso.

Conceito bastante polêmico, o letramento tem, na linha dos documentos governamentais, quem o defenda como parâmetro a ser tomado para avaliar o quanto de trabalho há de ser feito pela escola com 
cada estudante; há autores que tomam o conceito para criticar as reduções e relações de poder que a escola pode realizar em torno da língua escrita, anunciando outras possibilidades de trabalho; e há quem apenas denuncia o estabelecimento da cultura letrada como parâmetro social, como estratégia de desqualificação, de subjugo, de dominação das culturas iletradas.

São contribuições importantes para se pensar e aplicar nas escolas. A perspectiva da leitura dialógica, que apresentaremos na sequência, além de levar em conta tais preocupações, oferece ferramentas efetivas para lidar com os elementos que são objetos da denúncia ou do anúncio que o letramento faz.

\section{A LEITURA DIALÓGICA E SUAS CONCEPÇÕES}

A perspectiva dialógica da aprendizagem da leitura foi elaborada pelo Centro Especial de Investigação em Teorias e Práticas Superadoras de Desigualdades (CREA), da Universidade de Barcelona, e assenta suas bases na interação social entre as pessoas, mediada pela linguagem. É um processo não apenas de leitura, mas também de diálogo, por meio do qual as pessoas podem trocar ideias, aprender conjuntamente e produzir mais conhecimento, encontrando, assim, novos significados que transformam a linguagem e o conteúdo de suas vidas.

A leitura dialógica será apresentada neste artigo como uma possível contribuição para pensar o debate acerca da leitura. É assumida como uma nova forma de conceber a leitura, pois, na modalidade aqui focalizada, a da leitura de crianças e jovens na escola, centra seu objetivo num processo mais amplo, que engloba a socialização na leitura e a criação de sentido por parte das pessoas do entorno da escola.

De acordo com Valls, Soler e Flecha $(2008$, p. 3),

a leitura dialógica é o processo intersubjetivo de ler e compreender um texto sobre o que as pessoas aprofundam em suas interpretações, refletem criticamente sobre o mesmo e o contexto, e intensificam sua compreensão leitora através da interação com outros agentes, abrindo assim possibilidades de transformação como pessoa leitora e como pessoa no mundo.

O ler dialogicamente implica mover o centro do ato de significado de uma interação subjetiva entre a pessoa e o texto, em nível individual, para uma interação intersubjetiva entre crianças e ou pessoas jovens e adultas em relação a este mesmo texto.

As contribuições dos estudos de Soler (2001) para as investigações nesse campo são essenciais, pois evidenciam que a aprendizagem, 
especialmente da leitura, depende de muitos elementos que vão além das abordagens metodológicas de ensino de leitura na escola, que prezam desde o processo cognitivo de decodificação, passando pela experiência subjetiva do leitor, ou ainda o apoio por parte do professor.

A partir destes apontamentos, entende-se que o principal objetivo da leitura dialógica é o desenvolvimento de máxima aprendizagem dos conteúdos letrados como instrumentos fundamentais de emancipação na sociedade da informação. Pode-se levantar, de acordo com Elboj et al. (2002), três fatores essenciais para a aceleração da aprendizagem da leitura e da escrita desde um enfoque dialógico: superação do binômio tradicional educador/educadora - aluno/aluna; aumento das interações e fomento da aprendizagem instrumental.

As autoras afirmam ainda que a leitura dialógica não consiste simplesmente em dialogar sobre os textos que lemos. É preciso, também, considerar e efetivar as aprendizagens e assimilação de processos arbitrários de atribuição de valor sonoro convencional às letras que representam graficamente nossa linguagem. Ainda que vivamos em um mundo letrado, em um entorno cheio de letras e símbolos, aos quais atribuímos significados, isso não implica que a leitura possa ser aprendida espontaneamente. As crianças, os jovens e as pessoas adultas que aprendem o processo de leitura e escrita, o fazem a partir de interações e de compreensões sistematizadas.

Nesse sentido, o apoio na obra de Vygotsky (2009) e em sua consideração de que a aprendizagem não decorre do desenvolvimento orgânico, mas integra, de maneira universal e necessária, os processos culturalmente organizados, e especificamente humanos das funções psicológicas, nos auxilia nessa tarefa de reforçar a importância da leitura dialógica. A aprendizagem organizada se converte, para esse autor, em desenvolvimento mental e começa uma série de processos evolutivos que não poderiam se dar fora da aprendizagem (p. 137- 139).

Em pleno acordo com Vygotsky, é possível identificar que a educação entendida dessa maneira passa a ser uma das ferramentas para a transformação da sociedade, já que este autor acredita na mudança dos processos psicológicos através da transformação das interações do contexto e não da sua adaptação a ele: a aprendizagem desperta uma série de processos evolutivos internos capazes de operar somente quando a criança está em interação com pessoas de seu entorno e em cooperação com algum semelhante (mais capaz, ou seja, aquele mais experiente na cultura em que se está inserido). 
Nessa mesma linha de pensamento, identifico as contribuições de Freire $(1982,2005,2006)$, que assume a postura ética e política de entender os seres humanos como seres de transformação e não de adaptação. Este autor confia na capacidade de todas as pessoas em transformar a realidade, entendendo que a história é possibilidade e não determinação; e, também, na necessidade de uma educação que ofereça instrumentos para aprofundar a técnica do ler e do escrever.

Em concordância com esse autor, evidenciamos que a leitura dialógica, ao se centrar na prática da leitura, "prevê a necessidade de se dedicar um tempo considerável para repassar palavras, letras, sons, praticar diversos exercícios que reforcem aquilo no que a criança apresenta maior dificuldade" (ELBOJ et al., 2002, p. 115). No mesmo sentido das elaborações de Vygotsky (2009), as autoras ressaltam que a tutorização (acompanhamento, intervenção) feita por diferentes pessoas adultas e o grupo de iguais auxilia nesse processo.

Em síntese, pode-se afirmar que a discussão centrada no foco da leitura dialógica deixa claro que o que está em pauta não é a existência de um método concreto e correto de se fazer leitura, mas sim uma perspectiva que insista em assegurar uma organização das aprendizagens intensificando qualitativa e quantitativamente as ocasiões de aprendizagem dos mecanismos de leitura.

A partir desta introdução, descreveremos, na sequência, os resultados de uma pesquisa de doutorado 4 que evidencia uma forma de organização e criação de espaços dialógicos de leitura na sala de aula a partir de uma atuação concreta de êxito no âmbito da língua, da leitura e da literatura. A experiência, que revela um aumento do sentido da leitura e das aprendizagens instrumentais, tão necessárias na sociedade da informação, é a atividade denominada Tertúlia Literária Dialógica.

\section{A EXPERIÊNCIA COM LEITURA DIALÓGICA EM SALA DE AULA: AS TERTÚLIAS LITERÁRIAS DIALÓGICAS}

A Tertúlia Literária Dialógica nasceu no ano de 1978, na Espanha, como uma atividade cultural e educativa não formal, na escola de Pessoas Adultas "La Verneda de Saint Martí" (Barcelona). Ela é uma das atividades mais antigas e mais frequentadas desta escola por "pessoas do grupo de alfabetização e neoleitores, para ler obras clássicas de autores como Frederico García Lorca, Antonio Machado, James Joyce, Franz Kafka e tantos outros" (SANCHEZ-AROCA, M., 1999, p. 329). 
A tertúlia é uma atividade que se diferencia das demais não apenas pelo seu caráter dialógico, mas também pela sua organização e funcionamento. Uma definição bem clara de seu funcionamento pode ser encontrada nas palavras de Flecha (1997):

A Tertúlia Literária se reúne em sessão semanal de duas horas. Decide-se conjuntamente o livro e a parte a comentar em cada próxima reunião. Todas as pessoas leem, refletem e conversam com familiares e amigos durante a semana. Cada uma traz um fragmento eleito para ler em voz alta e explicar o significado atribuído àquele parágrafo. O diálogo vai sendo construído a partir dessas contribuições. Os debates entre diferentes opiniões se resolvem apenas através de argumentos. Se todo o grupo chega a um acordo, ele se estabelece como a interpretação provisoriamente verdadeira. Caso não se chegue a um consenso, cada pessoa ou subgrupo mantém sua própria postura; não há ninguém que, por sua posição de poder, explique a concepção certa e a errônea. (FLECHA, 1997, p. 17 e 18)

É importante esclarecer que a dinâmica da tertúlia segue a orientação dialógica, conforme vimos discutindo ao longo desse artigo. Flecha (1997), após longos estudos baseados na teoria de Freire e Habermas, sintetizou essa orientação dialógica em sete princípios, os quais podem ser descritos resumidamente da seguinte maneira:

- Diálogo igualitário: para que o diálogo seja igualitário é preciso considerar a função de validade de um argumento e não a posição de poder das pessoas que estão na interlocução; assim todas as pessoas podem aprender igualmente.

- Inteligência cultural: considera-se que todas as pessoas têm inteligência e que esta é reportada ao seu contexto cultural, assim todas têm igual condição de participar em um diálogo igualitário rechaçando-se a valoração social dada a determinados grupos privilegiados.

- Transformação: o homem e a mulher são seres de transformação e não de adaptação, e esta transformação se faz coletivamente, mediada pelo diálogo intersubjetivo, não acontece do dia para a noite, ela é resultado de um processo elaborado coletivamente.

- Criação de sentido: a criação de sentido implica que o sujeito se veja protagonista de sua própria existência, no sentido de dar uma determinada orientação vital a sua vida, que o diálogo com o outro se faça numa relação horizontal. 
- Solidariedade: as práticas educativas igualitárias só podem se fundamentar em concepções solidárias. A solidariedade é um recurso de mobilização, já que questiona o individualismo e, nesse sentido, deve-se enxergar a existência de um projeto igualitário de transformação social através da ação educativa.

- Dimensão instrumental: uma boa preparação acadêmica que enfatize a dimensão instrumental da aprendizagem é um elemento chave para minimizar os efeitos da exclusão social. A aprendizagem instrumental é aprofundada e intensificada quando situada em um marco dialógico.

- Igualdade de diferenças: a verdadeira igualdade inclui o igual direito de toda pessoa ser diferente, isso significa que todas as pessoas têm direito a uma educação igualitária, independente de seu gênero, classe social, idade, cultura, formação acadêmica. Através da diversidade se chega a uma situação de igualdade que não é homogênea.

Com base nesses apontamentos é possível entender que a leitura dialógica promovida pela prática da tertúlia pode ser realizada em sala de aula, mas não se esgota nesse espaço e vai mais além, adentrando os espaços da escola, da família, do bairro. As crianças, ao observarem as muitas coisas escritas em seu entorno, vão assimilando com as pessoas adultas que thes são próximas e com seus companheiros, enquanto perguntam, respondem e repetem.

Além disso, a leitura dialógica realizada na escola cria pontes e ações coordenadas entre escola e outros espaços que, além de multiplicar as interações e os momentos de aprendizagem, aumentam as experiências de leitura para todas as crianças (ELBOJ et al., 2002, p. 117).

Por esse motivo, é possível afirmar que a realização desta atividade em sala de aula de diferentes escolas potencializa e abre novos horizontes para a prática da leitura no âmbito escolar. Além da experiência inicial realizada na escola de Pessoas Adultas, "La Verneda de Saint Martí,, tal atividade vem sendo realizada, também, com pessoas adultas no Brasil, num trabalho cuja articulação é feita pelo Núcleo de Investigação e Ação Social e Educativa (NIASE/UFSCar).

O início da atividade de tertúlia literária dialógica em sala de aula, com crianças e adolescentes, deu-se a partir das experiências realizadas pelo professor basco Miguel Loza, que partiu de uma inquietação em relação à constatação sobre a maneira com que os adolescentes liam os livros na 
escola: de forma individual, sem diálogo igualitário, sem intervenção do aluno na eleição dos livros e com a obrigatoriedade de fazer uma ficha ao final da leitura.

Esta forma de lidar com a leitura, segundo Loza (2004), não dá nenhuma informação ao professor nem sobre a leitura realizada nem sobre como modificar as atitudes e a competência diante desta situação. Além disso, ele afirma que a leitura em sala de aula "não motivava os(as) alunos(as), e despertava atitudes negativas e imagens e autoimagens de déficit, consequentemente alimentava as premissas excludentes" (p. 69).

Tal experiência, por seu caráter positivo, espalhou-se por diversas escolas europeias e serviu de referência para o início do trabalho com as tertúlias literárias dialógicas em escolas brasileiras. A leitura nas escolas brasileiras tem gerado não somente a desmotivação, mas também altos índices de fracasso, o que nos faz deparar com professores desencantados e alunos com dificuldades de ler e entender o escrito.

A partir dessas inquietações foi possível iniciar a primeira experiência com leitura dialógica em sala de aula no Brasil, em uma escola localizada no interior do estado de São Paulo. Esta atividade iniciou no ano de 2007 e foi acompanhada e pesquisada em trabalho de doutorado e, ainda hoje, em 2011, a atividade é analisada e recebe orientação e formação por parte de pesquisadores do NIASE.

A ideia partiu de um desejo de ver ampliada a compreensão leitora das crianças e, também, as interpretações em torno de uma obra da literatura clássica, ao mesmo tempo que pudessem refletir criticamente sobre sua vida e a sociedade por meio do diálogo igualitário com outros leitores.

Tínhamos uma intuição de que, a partir dos diferentes conhecimentos de mundo que abarcam as diferentes inteligências culturais, as crianças pudessem criar mais sentido em suas relações e promover processos internos e externos de transformação.

Além disso, o livro de literatura clássica em sua dimensão instrumental, usado por muitas décadas para promover a seleção dos "mais capazes", poderia ser lido agora de maneira prazerosa, dialogada, compartilhada e instigante, quebrando assim o mito da impossibilidade de compreensão. A solidariedade abriria o caminho para a contemplação da unidade na diversidade, cabendo as diferentes opiniões e maneiras de falar.

Uma orientação para a realização de uma leitura dialógica é a de que ela só pode acontecer a partir do entendimento de que todos estes princípios não são apenas uma simples metodologia, mas uma necessidade para o estabelecimento da dinâmica em sala de aula. É importante destacar que o 
diferencial de uma leitura dialógica é a sequência com que tais princípios se organizam dentro da dinâmica da sala de aula, o que se diferencia de outros trabalhos com o mesmo sentido positivo.

O primeiro passo é a eleição dialogada entre professoras e crianças sobre o livro a ser escolhido para a leitura. A professora, na função de moderadora da atividade, leva para toda sua turma um pequeno resumo contendo alguns títulos de obras de literatura. Esta seleção é orientada pela professora, a partir do diálogo com as crianças sobre as possíveis leituras que gostariam de realizar, ou ainda sobre temas relacionados com assuntos que estejam trabalhando na sala de aula.

A partir da escolha do livro, a leitura é iniciada na própria sala, que está disposta em círculo, como forma de garantir maior interlocução entre todos os participantes; estando sentados uns ao lado dos outros, podem se ajudar no processo da leitura. Vygotsky (2009) nos ajuda a entender esse processo quando aborda a questão das interações como a base para que $o$ indivíduo possa compreender as representações mentais do seu grupo social e, a partir daí, aprender.

A quantidade de páginas para a leitura do dia é combinada com a turma. Mais que realizar a leitura perante as outras crianças, é importante deixar claro que em uma tertúlia prioriza-se a compreensão e o entendimento, que vai sendo ampliado na medida em que as discussões são orientadas por meio de uma dinâmica dialógica. Todos podem argumentar igualmente, e a professora responsável pela turma vai incentivando tal diálogo e a construção do entendimento por meio da aprendizagem instrumental.

Esta aprendizagem, segundo Vygotsky (2009), ocorre sempre na interação que se faz na presença do outro social e, também, na presença da linguagem. A ideia do outro social, apresentada a partir das ideias desse autor, refere-se ao conhecimento construído na mediação entre o indivíduo e os demais sujeitos e, também, entre o sujeito e um elemento do ambiente e da cultura. Nesse sentido, o papel do professor mediador da tertúlia é fundamental.

Nesta dinâmica de leitura dialógica é essencial que se estimule a leitura a cada encontro, até que a criança possa adquirir coragem e fazer as primeiras leituras. Para isso, é necessário um ambiente de respeito e diálogo, pois todas as crianças têm o mesmo direito de ler, incluindo aquelas em fase inicial de alfabetização. As crianças se encorajam, na medida em que percebem na turma força e apoio para sua aprendizagem.

Após a leitura, as crianças elegem um parágrafo que tenha chamado sua atenção e comentam as questões sobre entendimento, ou ainda, dúvidas, 
além de fazerem conexões com as questões referentes aos seus âmbitos da vida. Os temas variam desde aventuras, amor, saudade, ecologia, família, animais etc. É importante que argumentem diante do parágrafo escolhido e que apontem questões que estejam relacionadas a alguma problemática (social ou de outra ordem) e que lhes façam sentido.

Cabe destacar que cada criança tem seu pedido de fala anotado pela pessoa moderadora, que é o responsável por conceder a palavra e organizar a dinâmica. Este moderador pode ser a professora, um familiar que entra para colaborar na aula, ou ainda uma criança mais experiente na temática. É essencial que o moderador conheça bem a dinâmica e os princípios da aprendizagem dialógica, para que a leitura se faça dialógica e não se priorize umas falas em relação a outras, nem mesmo algumas pessoas em detrimento de outras. $O$ papel da professora, aquela que tem maior conhecimento instrumental com relação às crianças, não pode ser omitido, 0 que significa que proceder de modo dialógico é também esclarecer conteúdos equivocados que, às vezes, são gerados em função de um destaque.

Ela tem o papel também de estimular as crianças para que pensem nas questões postas pelos livros e, somando-se a isso, de provocar inquietações e lançar perguntas para a turma; ou seja, além de estar o tempo todo inteirada da história, a moderadora tem como objetivo fazer com que as crianças alcancem o máximo possível de conhecimentos instrumentais e os conectem com as questões sobre a vida e a sociedade.

$\mathrm{Na}$ tertúlia literária dialógica podemos comentar tudo o que pensamos durante a semana: coisas que pesquisamos sobre o assunto; as conversas compartilhadas com nossos familiares e amigos sobre a leitura realizada em sala; recordações de momentos ou situações, já que o mesmo livro pode despertar diferentes sensações em cada pessoa que o lê. A prioridade é a leitura dos denominados clássicos da literatura universal ${ }^{5}$ por entender que este tipo de leitura foi considerado, durante muito tempo, de acesso restrito às pessoas com alta escolaridade, resultado de uma situação em que se determina quem pode ler o quê. Assim, o que sempre se leu na escola foi determinado por uma classe privilegiada: branca, masculina, com descendência européia. Dessa forma, o acesso aos clássicos significa romper com este ciclo de exclusão.

Um dos objetivos centrais em uma tertúlia é que se aprenda mais e melhor a partir da uma interação intersubjetiva; é o que poderemos acompanhar a seguir. 


\section{DISCUSSÃO E ALGUNS RESULTADOS}

Como vimos construindo no decorrer deste texto, a escola, lugar privilegiado do desenvolvimento dos processos do ler e do escrever, pode apoiar inúmeras outras aprendizagens. Nesse sentido, a questão inicial que instigou a busca científica e prática, para elaborar uma tese sobre a leitura dialógica foi pensar: De que maneira a leitura dialógica, por meio de Tertúlia Literária Dialógica, pode promover melhoria na aprendizagem das crianças e no trabalho de professoras em sala de aula?

Para isso, como objetivo geral buscou-se identificar e analisar as transformações das práticas educativas das professoras e das crianças a partir da realização de Tertúlia Literária Dialógica no contexto da sala de aula.

E, como objetivos específicos, buscou-se:

- caracterizar as práticas de leitura já existentes no ambiente das crianças (escolar e familiar);

- identificar e sistematizar transformações das práticas de leitura em sala de aula, a partir do desenvolvimento da leitura dialógica promovida pela Tertúlia Literária Dialógica;

- descrever e analisar aprendizagens docentes a partir da dinâmica da leitura dialógica em sala de aula.

Para a realização desta pesquisa utilizamos a metodologia comunicativo-crítica, elaborada pelo Centro Especial de Investigação em Teorias e Práticas Superadoras de Desigualdades (CREA) da Universidade de Barcelona/ Espanha, uma vez que que esse é um dos modos de investigar a realidade, com base no diálogo e na transformação social. Essa metodologia possibilita a sustentação tanto do trabalho teórico quanto do trabalho de campo. Foi elaborada a partir das contribuições de inúmeros autores, especialmente da teoria da ação comunicativa de Habermas (1987) na área da filosofia e sociologia, e de Freire $(1982,2005,2006)$ na área da educação.

A investigação foi realizada durante o segundo semestre de $2008 \mathrm{em}$ duas salas de aula de uma escola pública da cidade de São Carlos/SP, coletando informações com as professoras e seus alunos, através dos relatos da vida cotidiana, grupos de discussão com as crianças e observação comunicativa da aula, uma vez na semana, com a duração de uma hora em média.

De acordo com Gómez et al. (2006), a análise realizada por meio da metodologia comunicativa-crítica está condicionada pela dimensão excludente e pela dimensão transformadora. A primeira diz respeito às 
barreiras que impedem a transformação e a segunda refere-se às vias que permitem superá-las.

Como dimensões de exclusão foi possível identificar algumas relações antissolidárias em sala de aula; a dificuldade inicial em criar espaços de diálogos com as crianças e orientá-las para isso; o medo em lidar com uma atividade nova na sala de aula por parte das professoras; e a insatisfação em não poder trabalhar com os clássicos da literatura, pela quantidade insuficiente disponibilizada nas prateleiras das escolas. A leitura foi reconhecida como atrelada aos fins educativos, porém a relação entre o instrumental e as questões efetivas da aprendizagem foi apresentada, ainda, como insuficientes.

Já a condução dialogada da atividade trouxe vários resultados: apoio para a aprendizagem instrumental; destaque para o papel da professora na função de moderadora e mediadora do conhecimento e incentivadora do gosto pela leitura; evidências do diferencial desta dinâmica para se trabalhar as questões da leitura em sala de aula; a interação com pessoas mais experientes e com os pares na ampliação do aumento da aprendizagem instrumental; o diálogo em torno das obras clássicas e sua relação com a vida. Várias dessas questões se apresentaram ao longo do processo como dimensões transformadoras. Identificamos, também, a importância da família no incentivo e na criação do gosto pela leitura realizada na escola.

É possível, assim, constatar que o tema da leitura em sala de aula, associada ao processo de entendimento do mundo e não somente da palavra escrita, vem sendo pouco investigado em âmbito nacional. Nesse contexto, o objetivo deste artigo foi o de expor uma pesquisa em que se trabalha o ensino da leitura através das interações com o livro, a necessária mudança da prática pedagógica docente, de maneira geral, e a forma de tratar a leitura em sala de aula através da introdução das tertúlias literárias dialógicas, com criança em idade escolar.

A percepção da necessidade de uma mudança no foco de ensino e da aprendizagem da leitura tem se apresentado nas últimas décadas em vários estudos sobre letramento e alfabetização, entre os quais os de Soares (2009). As políticas públicas também vêm introduzindo reformas e orientações através de documentos ( $\mathrm{PCN}$ ) e da produção de material de referência para o trabalho do professor em sala de aula. Apesar deste esforço para a superação da leitura mecanicista, existem ainda alguns limites, que estão, sobretudo, na falta de entendimento da questão política da educação, da sua não neutralidade (FREIRE, 2003). 
Falta ainda na rede de ensino a concepção de leitura como leitura do mundo e leitura da palavra (FREIRE \& MACEDO, 2006), ou seja, a compreensão de que é bastante restritivo ter acesso ao significado do que se lê apenas por meio da leitura da palavra. A leitura dialógica, por sua vez, implica, primeiramente, ler o mundo no qual tais palavras existem para poder transformá-lo.

\section{THE TEACHING OF READING TO CHILDREN IN THE CLASSROOM: DIALOGIC LITERARY GATHERINGS}

ABSTRACT:This article sets out to present the results of a doctoral research (2011) on the theme of dialogical reading. It deals with the reading of classical literature to enhance learning and make connections with life. Analyses being undertaken nationally in the field of advances in reading and writing have been included in order to broaden the debate. The research was initially pioneered in two public school classrooms in the State of São Paulo, using the communicative-critical methodology as a guideline, based on the analysis of reality in partnership with the subjects. The results highlight the positive impacts of a dialogical reading on teaching practices in the context, and in children's learning in the classroom.

KEYWORDS: Reading. Dialogue. Literature. Classroom.

\section{NOTAS}

1. As citações de obras editadas em língua estrangeira aparecem neste artigo em tradução livre da autora.

2. Foi realizada uma busca em artigos científicos dos principais periódicos de alcance nacional: caderno Cedes; Revista Brasileira de Educação; Educação e Sociedade; Cadernos de Pesquisa; Educação e Pesquisa; além das produções elaboradas nas principais universidades públicas do país.

3. Soares (2003) indica que a invenção do termo letramento, no Brasil, se deu em meados dos anos de 1980. Tal discussão surgiu associada ao conceito de alfabetização, o que tem levado a uma inconveniente confusão acerca dos dois processos, com a prevalência do conceito de letramento, o que, segundo ela, conduz a um apagamento da alfabetização.

4. Cf. a tese de Girotto (2011), defendida sob orientação da Profa. Dra. Roseli Rodrigues de Mello.

5. Entendemos que os livros de literatura clássica, que transpassam tempo e espaço, podem oferecer muito mais elementos para se pensar a vida. Entende-se por clássicas as obras de literatura nacional e estrangeira que, por mais que tenham sido escritas há décadas, permitem discutir questões da atualidade. 


\section{REFERÊNCIAS}

AUBERT, Adriana et al. Aprendizaje dialógico en la sociedad de la información. Barcelona: Hipatia, 2008.

BRASIL. Ministério da Educação. Parâmetros Curriculares Nacionais. Língua Portuguesa. 3. ed. Brasília: Secretaria da Educação Fundamental, 2001.

CASTELLS. Manuel. Flujos, redes y identidades: una teoría crítica de la sociedad informacional. In: CASTELLS, M. et al. Nuevas perspectivas críticas en educación. Barcelona: Paidós, 1994 .

ELBOJ, Carmen et al. Comunidades de aprendizaje: transformar la educación. Barcelona: Graó, 2002.

FLECHA, Ramón. Compartiendo palabras: al aprendizaje de las personas adultas a través del diálogo. [s.l.]: Paidós, 1997.

FREIRE, Paulo. A importância do ato de ler: em três artigos que se completam. 49. ed. São Paulo: Cortez, 1982.

FREIRE, Paulo. Pedagogia do oprimido. 42. ed. Rio de Janeiro: Paz e Terra, 2005.

FREIRE, Paulo. Pedagogia da autonomia. São Paulo: Paz e Terra, 2003.

FREIRE, Paulo; MACEDO, Donaldo. Alfabetização: leitura do mundo e leitura da palavra. 3. ed. Rio de Janeiro: Paz e Terra, 2006.

GIROTTO, Vanessa, C. Leitura dialógica: primeiras experiências com tertúlia literária dialógica com crianças em sala de aula. Tese (Doutorado em Educação) - Programa de Pós-Graduação em Educação da UFSCar, São Carlos/SP, 2011.

GÓMEZ, Jesus et al. Metodologia comunicativa crítica. Barcelona: El Roure, 2006.

LOZA, Miguel. Tertúlias Literárias. Cuadernos de Pedagogía, n. 341, p. 66-69, 2004. Disponível em: <http://www.isftic.mepsyd.es/formacion/materiales/126/cd/unidad_9/ materiales_m9/sabermas1.pdf>. Acesso em: 25 maio 2005.

HABERMAS, Jurgen. Teoria de la acción comunicativa: crítica de la razón funcionalista. Madrid:Taurus, 1987.

SÁNCHEZ-AROCA, Montse. La Verneda St Martí: una escuela donde las personas se atreven a soñar. Harvard Educational Review, v. 69, n. 3, p. 320-335, 1999.

SOARES, Magda. Letramento: um tema em três gêneros. 3. ed. Belo Horizonte: Autêntica, 2009.

SOARES, Magda. Letramento e alfabetização: as muitas facetas. $26^{a}$ reunião da ANPED. Poços de Caldas, 2003. Disponível em: <http://www.anped.or.br>. Acesso em: maio 2010.

SOLER, Marta. Dialogic Reading: a new understanding of the reading event. Tese (Doutorado) - Harvard University, Cambridge-MA, 2001. 
VYGOTSKY, Lev Semenovitch. El desarollo de los procesos psicológicos superiores. Barcelona: Crítica, 2009.

VALLS, Rosa; SOLER, Marta; FLECHA, Ramón. Lectura dialógica: interacciones que mejoran y aceleran la lectura. Revista Iberoamericana de Educación, n. 46, jan./abr. 2008. Disponível em: <http://www.rieoei.org/rie46a04.htm>. Acesso em: 8 fev. 2010.

Vanessa CRIStina Girotto é Pedagoga: formada pela UFSCar, tendo concluído mestrado em 2007, e doutorado em 2011, na mesma Universidade. Trabalha com questões voltadas à alfabetização de crianças, jovens e adultos, na vertente dialógica. É integrante e pesquisadora do Núcleo de Investigação e Ação Social e Educativa (NIASE/UFSCar), desde 2004. Professora da UNIFAL-MG.

E-mail: vanessagirotto@yahoo.com.br

Rosel Rodrigues de Mello é professora efetiva da UFSCar, desde 1992. Ocupa atualmente o cargo de professora associada nível 3, junto ao Departamento de Teorias e Práticas Pedagógicas. Atua na Licenciatura em Pedagogia, na Didática Geral das outras Licenciaturas, e na Pós-Graduação em Educação, em que orienta mestrado e doutorado. Fundadora (2002) e coordenadora do Núcleo de Investigação e Ação Social e Educativa (NIASE), atua nas seguintes linhas de pesquisa: ensino e aprendizagem, correntes pedagógicas, aprendizagem dialógica, comunidades de aprendizagem, educação de adultos, democratização do conhecimento escolar, tertúlia literária dialógica.

E-mail: roseli@ufscar.br 